\title{
Neurological and psychiatric aspects of open-heart surgery
}

\author{
SAMUEL I. COHEN ${ }^{1}$ \\ From the Maudsley and Brompton Hospitals, London
}

The common aim of all the work that has gone into the development of open-heart surgery, and in particular the development of pump-oxygenators and hypothermia, has been to ensure that the brain does not suffer damage during operations on the heart. Even with these advances in technique, as the Lancet (1964) has recently pointed out, 'the hazards to the nervous system during cessation of cardiac and pulmonary activity are clearly not entirely dispelled'. It is therefore surprising to find that relatively little has been done to establish whether the function of the brain is unimpaired after these operations.

At the Brompton Hospital the physicians and surgeons of the Cardiac Department had been concerned by the possibility that some of their patients might be, as they put it, 'not quite the same' after open-heart operations, and it was at the suggestion of the late Dr. Paul Wood that the present work was undertaken.

Two main types of surgical technique were in use. In the first, hypothermia to about $30^{\circ} \mathrm{C}$. was induced, either by a method of surface cooling or by diversion of caval blood through a cooling element (veno-venous cooling). In the second technique, a by-pass circulation was maintained using the Melrose-N.E.P. heart-lung pumpoxygenator with or without hypothermia. In the first technique, it was necessary to arrest the circulation during the procedure on the heart, whereas in the second no arrest of the circulation was necessary.

A few authors (Björk, Aletras, and Intonti, 1962 ; Ehrenhaft, Claman, Layton, and Zimmerman, 1961 ; Silverstein and Krieger, 1960 ; Silverstein, Jacobson, Kreel and Krieger, 1960) have reported cerebral complications of open-heart surgery, varying in incidence from $5 \%$ to over $25 \%$. The most comprehensive paper is that of Ehrenhaft et al. (1961), who report 19 cases of

1 Present address: Department of Psychiatry, The London Hospital, E.1 cerebral complication out of 400 operations. These patients suffered from 'convulsions, hemiparesis, coma, prolonged drowsiness, confusion, memory defects', and all are said to have recovered completely in from a few days up to three weeks. However, it is clearly a neurological recovery and not a total recovery that is being described, since one patient who had been lethargic and disorientated is said to have recovered completely but to have been left with a 'post-operative senile psychosis'. In other papers in which recovery is said to have been complete after a variety of neuropsychiatric symptoms, the evidence for this is not stated (Björk et al., 1962; Sloan, Morris, Mackenzie, and Stern, 1962). No study by a psychiatrist has been published.

This paper reports an attempt to answer the questions whether patients undergoing open-heart operations suffer any psychiatric disturbance, particularly of a permanent type, as a result, and, if they do, whether it can be attributed to the hypothermia or to the use of the pump.

\section{METHOD}

One hundred consecutive patients were examined between July 1960 and October 1961. A full psychiatric assessment was made before operation at an interview structured by the use of a questionnaire. This took about half an hour and comprised medical, intellectual, social, and emotional data, including details of the precise level of attainment at school or at work, level of earnings, interests, reading, ability to concentrate, memory, social activities, and history of mental disturbances. After the operation all patients were seen while they were still in hospital and again at follow-up. In view of the known nonspecific effects of any operation, the minimum followup period was sct at six months, and, in cases of doubt, the follow-up has been extended to two years. Where it seemed desirable, both before and after the operation, a parent, spouse, or other suitable informant was seen, and in the case of a number of 
children, reports from the school were obtained. Children under 7 years were excluded, as was the substantial number of patients from abroad, in whom follow-up was not possible.

\section{RESULTS}

There were 21 deaths within a day or two of the operation, mostly in patients who had been very ill. Fifty of the survivors had had by-pass operations and 29 had had hypothermia alone. Of the latter, 19 were cooled by the veno-venous method and 10 by the surface method. Their ages ranged from 7 to 55 , although only seven were over 40 years of age. In five of the survivors the cardiac lesion was rheumatic, and in the remainder it was congenital. Of the 79 survivors, 69 have been followed up personally and nine by post. One refused follow-up.

HYPOTHERMIA PATIENTS All 29 of the hypothermia patients are psychiatrically well and are functioning at or above their previous levels. Two of them had transient post-operative anxiety states, one a brief post-operative depression, and one developed hysterical blindness soon after her operation. Two developed difficulties with memory, which subsequently cleared, and their assessment is discussed below (cases 6 and 7).

BY-PASS PATIENTS Of the 50 patients, 42 are completely well. Two of these developed symptoms that illustrate some of the difficulties of assessment, but they recovered completely. They are discussed below (cases 8 and 9). Three died within a few months of the operation and, as far as one could tell, they were mentally normal. The remaining five patients suffered permanent neuro-psychiatric damage (cases 1 to 5).

Case 1 A man, aged 20, suffering from pulmonary stenosis and a ventricular septal defect. The postoperative course was stormy, with haemorrhage, prolonged hypothermia, left-sided Jacksonian fits, and drowsiness. He had a residual left-sided hemiparesis, which had largely but not completely recovered when he was followed up six months later; psychiatrically he was normal.

Case 2 A girl, aged 16, suffering from an atrial septal defect. She recovered completely after her operation and was psychiatrically normal. However, she developed an empyema, and three weeks after the operation, while this was being aspirated, she became hemiplegic and aphasic and has remained so.

Case 3 A woman university graduate of 32 , suffering from severe calcified aortic stenosis. Twenty minutes after taking down the by-pass, when the heart's action seemed good, ventricular fibrillation occurred. This lasted for 27 minutes, and subsequently sinus rhythm was restored. The electrocardiogram showed the picture of a posterior cardiac infarction, and it was considered that this was due to coronary embolism. In the next few days it was difficult to maintain a satisfactory blood pressure, and during this time she developed a right hemiparesis and aphasia. After 14 months she was physically well but was unable to run her home unaided and could not manage her housekeeping money.

Case 4 A married woman of 35 suffering from an atrial septal defect. After 12 months she was forgetful, she would forget where she had put things, for example, her children's clothes, or would forget to buy something when she was shopping. She had never been like this before her operation. She had also noticed that since her operation her periods lasted two days instead of five. After 21 months her periods were lasting five days, but her forgetfulness was unchanged. She managed her home, read a good deal, and had no difficulty in concentrating on her reading. Her post-operative course had been difficult and she had required treatment in an oxygen tent for four weeks. Case 5 A man of 47 suffering from mitral disease. He was intellectually impaired and had a declining work record before his operation. Possibly he had been having small cerebral emboli. Afterwards he seemed more impaired mentally, but it was difficult to be sure and he refused further investigation.

In three of these five patients there were definite signs, in the form of hemiplegia, of injury to the brain. In one there was a suggestion that the pituitary may have suffered, and in the fifth the result is indeterminate, as he refused investigation and follow-up.

DIFFICULTIES IN ASSESSMENT The problem has been to decide whether changes in mental function reported by the patients are the result of damage to the brain or not. Impairment of memory, concentration, or ability to calculate, for instance, although rightly regarded as characteristic features of 'organic' mental states, may very often be present in anxiety states and depression, and both these conditions not infrequently follow surgical operations. The following histories illustrate this $\frac{D}{O}$ problem.

Case 6 A grammar-school girl of 15 suffering from an atrial septal defect, which was closed under hypothermia induced by veno-venous cooling. The patient, $N$ her parents, and friends noticed that she was forgetful $O$ for two months after the operation. However, after six months her memory was normal and her school work was up to its pre-operative level. The time of occlu- $\mathbb{D}$ sion of the circulation during closure of the defect?

was $9 \frac{1}{4}$ minutes. from an atrial septal defect, closed under hypothermia $\bigcirc$ induced by veno-venous cooling. Nine months after $\mathbb{\Phi}$ the operation she said that she was forgetful and $\frac{0}{0}$ 
needed to keep a memo-pad with her constantly when at work, although otherwise her work was at least as good as it had been before the operation. The difficulty was still present after 11 months, but had cleared after 14 months. The time of the occlusion of the circulation was $8 \frac{3}{4}$ minutes.

The times of occlusion in these two patients were the longest in the hypothermia group, the longest time in the remaining 27 patients being 7 minutes. In neither patient was there any evidence that the memory defect could have been due to emotional factors, and it is likely, though by no means conclusive, that it was due to anoxic damage to the brain.

Case 8 A student of aeronautical engineering, aged 19 , suffering from pulmonary stenosis, who had just successfully completed his first year at the university. He was an anxious man and came from a neurotic family. The operation was performed under by-pass in the summer vacation, 1960, but he did not return to college until the middle of the autumn term. At that time he felt tense and restless and could not settle down. He was never able to catch up and failed all his examinations during the ensuing academic year. He said that, although he seemed to be studying normally and to be taking things in, he would find that a few days after he had learned something, he would not only be unable to remember it, but he would even have forgotten that he had ever seen it. As the year went by he became increasingly anxious and he feared he would lose his grant. When he had entered the university he had, as it happens, been one of a group given psychological tests experimentally by Dr. Furneaux, of the Maudsley Hospital. Fortunately these results were available, and when the tests were repeated it was seen that, although his level of performance was adequate, his accuracy decreased markedly under stress, whereas in the original tests it had decreased only slightly. His anxiety was greatly relieved when the university was persuaded to allow him to repeat the year, and in the following mid-sessional examinations he came top in several subjects and did particularly well in mathematics.

It seems likely that the difficulty with memory was attributable to his marked anxiety and consequent difficulty in concentration and most unlikely that his brain had been damaged.

Case 9 A boy of 8 suffering from ventricular septal defect which was closed under by-pass. After the operation he had a prolonged period of post-operative hypotension during which he developed a right hemiparesis and was in a coma of varying depth for several days. He finally recovered from this, but after six months his mother said he was unable to concentrate on anything for more than a few minutes; he looked at pictures in books instead of reading, whereas previously he had been top of his class in reading, and his arithmetic was poorer than it had been. After the operation his mother had been extremely anxious that he might have been impaired mentally, watched every detail of his behaviour for evidence of this, restricted his activities beyond what was medically necessary, and treated him like a baby. The anxiety became transmitted to the patient, and a vicious circle seemed to be set up, in which increasing anxiety led to increasing difficulty in concentrating. His performance at school continued to be considerably below its pre-operative level until about a year after the operation, but with individual attention from his teachers his work began to improve, his mother's anxiety subsided, and after 18 months he was working well. At that time the results of attainment tests in all his school subjects, and his I.Q., had recovered to their pre-operative levels.

The probability here is that the emotional factors were sufficient to explain his poor performance, but it is admittedly impossible to be certain that he had not suffered permanent damage to the brain.

\section{DISCUSSION}

In a discussion of the sequelae of concussion, $\mathrm{Sir}$ Charles Symonds (1962) has pointed out that the earliest symptoms to be expected from such a diffuse cerebral loss would be of the kind most difficult to measure-subjective difficulty over intellectual problems and slight personality changes'. The situation in the case of cerebral anoxia is similar and has influenced the choice of the clinical method in this study. No psychological test at present available would detect changes of this degree, and a normal electroencephalogram (E.E.G.) would not exclude brain damage. Serial E.E.G.s might provide useful evidence, but the facilities were not available.

All four patients with persistent psychiatric abnormality had some severe post-operative complication that could account for it by damage to the brain. In no case where the operation was uneventful was there any hint of psychiatric damage, so that there is no evidence to suggest that the techniques of hypothermia or by-pass are in themselves harmful to the brain. However, the method, although the only one available, is crude. Brierley (1963) has pointed out that in some of his patients who died after open-heart surgery the changes he describes in the brain are present in some degree, even where the cause of death was cardiovascular, and the Lancet (1964), commenting on this, suggests that 'many patients who survive these operations will have some cerebral impairment'. It is therefore encouraging that the incidence of detectably impaired cerebral function has been found to be so low in this study. How- 
ever, perhaps we should add cases 6,7 , and 9 to the group of brain-damaged patients. Although they appear to have compensated adequately at present for any brain cells they may have lost, it is conceivable that when the normal reduction in the number of cells takes place in later life, defects may become apparent. The times of occlusion in cases 6 and $7,8 \frac{3}{4}$ and $9 \frac{1}{4}$ minutes respectively, correspond with other evidence that the maximum safe time of occlusion at $30^{\circ} \mathrm{C}$. is 7 minutes (Thies and Wiemers, 1961 ; Waddell, Fairley, and Bigelow, 1957).

Thus there is a small but appreciable neuropsychiatric morbidity to take into account when advising such operations. This occurs only in patients in whom the operation is in some way complicated, and some of it would not be noticed in the ordinary way in a medical or surgical follow-up clinic. Cases 8 and 9 in particular illustrate the need for a long follow-up period and for adequate psychiatric assessment leading to proper rehabilitation. This morbidity is, of course, to be set against the undoubted and dramatic physical, social, and psychological improvement which results from these operations and with which one could not fail to be impressed.

\section{SUMMARY}

A psychiatric study is reported of 79 survivors of 100 patients who underwent open-heart surgery consecutively, and in whom the techniques of hypothermia and/or extracorporeal circulation were used. Medical, intellectual, social, and psychiatric data collected before operation were compared with similar data collected for up to two years afterwards. In no case where the operation was uncomplicated was there any evidence of psychiatric damage, so that there was no evidence that the techniques were in themselves harmful.

Four of the five patients who had post-operative neuropsychiatric complications were left with permanent mental impairment. Four suffered impairments from which they recovered completely. In two of these it was thought that the circulation had been occluded for longer than was safe at $30^{\circ} \mathrm{C}$., and the possibility that they may show defects in later life is discussed ; in one, the intellectual difficulties were due to emotional factors, and in one, it was not possible to be sure of their cause.

Difficulties in assessment and the need for a long period of follow-up and proper rehabilitation are discussed.

I am grateful to the physicians and surgeons of the Brompton Hospital for their willing co-operation, and to Dr. Michael Shepherd, of the Institute of Psychiatry, and the late Dr. Paul Wood for making the study possible.

\section{REFERENCES}

Björk, V. O., Aletras, H., and Intonti, F. (1962). The use of hypothermia in open heart surgery. J. cardiovasc. Surg. (Torino), 3 182 .

Brierley, J. B. (1963). Neuropathological findings in patients dying after open-heart surgery. Thorax, 18, 291

Ehrenhaft, J. L., Claman, M. A., Layton, J. M., and Zimmerman, G. R. (1961). Cerebral complications of open-heart surgery: further observations. $J$. thorac. cardiovasc. Surg., 42, 514.

Lancet (1964). (Leading article), 1, 89.

Silverstein, A., Jacobson, E., Kreel, I., and Krieger, H. P. (1960) Effects on the brain of extracorporeal circulation in open heart surgery. Neurology, 10,987.

and Krieger, H.P. (1960). Neurologic complications of cardiac surgery. Arch. Neurol. (Chic.), 3, 601.

Sloan, H., Morris, J. D., Mackenzie, J., and Stern, A. (1962). Openheart surgery: results in 600 cases. Thorax, 17, 128.

Symonds, C. P. (1962). Concussion and its sequelae. Lancet, 1, 1.

Thies, H., and Wiemers, K. (1961). Neurologische Untersuchungsergebnisse und E.E.G.-Befunde bei in Hypothermie operierten Patienten mit angeborenen Herzfehlern. Thoraxchirurgie, 8, 531 Waddell, W. G., Fairley, H. B., and Bigelow, W. G. (1957). Improved management of clinical hypothermia. Ann. Surg., 146, 542. 